\title{
Georgian Labour Market during the Coronavirus Pandemic
}

\author{
Nino Paresashvilii", Nino Abesadze ${ }^{2}$, Rusudan Kinkladze $^{3}$, Ketevan Chitaladze ${ }^{2}$, and Teona \\ Edzgveradze 4 \\ ${ }^{1 *}$ Ivane Javakhishvili Tbilisi State University, Faculty of Economics and Business, Department of \\ Business Administration, 2, University Str. Tbilisi 0186, Georgia \\ ${ }^{2}$ Ivane Javakhishvili Tbilisi State University, Faculty of Economics and Business, Department of \\ Economics, 2, University Str. Tbilisi 0186, Georgia \\ ${ }^{3}$ Georgian Technical University, Faculty of Business Technology, Department of Business \\ Administration, 77, Kostava Str., Tbilisi 0160, Georgia
}

\begin{abstract}
.
Research background: The paper analyzes and assesses the current situation in the Georgian labor market in the conditions of the pandemic. The article discusses the current, post pandemic state of the labour market in Georgia and the outcomes, impacts of Covid-19 on socio-economic situation.

Purpose of the article: According to the present situation, it is necessary to create institutions and mechanisms that will ultimately provide the public as well as private sectors with highly qualified workforce, increase the efficiency of organizations and at the same time reduce unemployment. Since the progress of the labour market hinges crucially on higher education systems, it is necessary for educational organizations to take decisions and specific actions in accordance with the challenges of the global environment. One of the main priorities of the "Georgia 2020" strategy is the development of human capital.

Methods: In the article the above-mentioned issues are discussed based on the statistical analysis which describes the challenges in almost every direction. There are revealed the results of the Coronavirus Pandemic. It is very interesting to picture the comparison between the previous and post pandemic situation in Georgia.

Findings \& Value added: It is necessary to prepare training courses and specialists according to the current requirements of the labour market. Moreover, specific steps and recommendations are given in the article which are needed to be taken into consideration by the Government of Georgia.
\end{abstract}

\footnotetext{
${ }^{1}$ Corresponding author: nino.paresashvili@tsu.ge
} 
Keywords: Post Pandemic State; labour market; workforce;
unemployment

JEL Classification: $J 01 ; J 64$

\section{Introduction}

In the conditions of modern globalization, human capital is the most important factor in terms of the competitiveness and development of the country and its economy in the world market. The social protection system pursued by the state has only had a short-term effect.

Restrictions introduced by the government institutions in the country in early 2020 have had a negative impact primarily on small businesses and the self-employed population, as a large army joining the ranks of the unemployed people [1-3]. Study of unemployment has a great practical value not only in respect of a country in general, but also in regional, gender, age and urban and rural respects [4]. Agriculture is a traditional sector and it has always played an important role in economic and social development of Georgia [5]. But underdeveloped grocery supply chain, absence of usage of modern technologies and technological opportunities in agricultural sector, small share in the budget for funding agriculture, incomplete and ambiguous regulatory laws, low level of compatibility with legislation of international markets, underdeveloped system of insurance in agriculture are still the problems in this sector [6-7]. Also, Food safety and protecting the phyto-sanitarian regulations are being attached great importance especially today as the space of economic integration into European Union is systematically increasing, also the share of the member countries of European Union in export and import is increasing and the food products take up more space in the import products [8]. What is more, in the pandemic, it is also important to produce agro products in agriculture in terms of employment, which also ensures the satisfaction of the local population with agricultural products.

COVID-19 has shifted a significant portion of business around the world into a phase of economic uncertainty. The declared pandemic found active areas of activity in the dormant phase, which led to a decline in employment applicants. Georgia, where the problem of unemployment is the main challenge of any government, could not miss these processes. Given the current epidemiological situatin and the fact that Georgia is on the list of safe countries, expectations are positive for the revival of business, although certain restrictions will be necessary in accordance with the regulations. It should be noted that The statistics of incomplete employment and hidden unemployment are not produced, which does not allow providing a comprehensive description of the situation in this regard.

\section{Methods}

In the article there is used the following methods: statistical analysis according to the official data of Georgia, comparative analysis in the dynamic of several years in order to highlight the trend of development of different indicators of labour market in Georgia. Analytical interpretation of other research reports of local as well as foreigner scientists, research organizations, field state departments. 


\section{Results}

There may be underlined several significant results based on the information gained during the working process on this article:

- Coronavirus-caused pandemic has had a negative impact on the labour market statistics of the country

- Quantitative indicators of business activity were reduced and, consequently, the number of employees was reduced

- The introduced regulations also framed the activities of the self-employed, which limited the economic parameters of their activities. As a result, the number of employees has significantly decreased and the level of real unemployment in the country has increased. It is unfortunate but the fact is that this had a direct impact on the deterioration of the population which limited their labour rights, the area of health care use, reduced incomes to a minimum, and so on.

- According to official statistics: In the second quarter of 2020, the unemployment rate in Georgia increased by 0.9 percentage points compared to the same period of the previous year and amounted to 12.3 percent.

- In the second quarter of 2020 the employment rate decreased by 0.5 percentage points to $55.9 \%$. In the II quarter, compared to the corresponding quarter of the previous year, the share of employees in the total employment rate decreased by 1.6 percentage points to $48.6 \%$

- In 2012-2019, the economically active population decreased by 106.8 thousand or 2.8 percentage points

- The number of employees decreases every year in accordance with the reduction of the economically active population (labour force). In particular, in 2016-2019, the number of employees decreased by 43.6 thousand or 1.8 percentage points.

- In 2019, the employment rate was reduced at the expense of hired employees. In particular, in 2019, compared to 2018, the number of employees decreased by 4 thousand.

- From 2017, the number of employees in the public sector is increasing every year, while in the private sector it is decreasing.

\section{Discussion \& Conclusion}

Today's official statistics show an incomplete picture of unemployment and employment on the one hand, and, on the other hand, due to the lack of relevant information, it is a hindering factor for the implementation of an effective state policy [9]. Also, it should be noted that employment policy in Georgia has a specific character. There are no so-called employment policy mechanisms. Ready-made recipes. Even if there are models developed in countries with market economies developed during the post-pandemic period, barriers to their mechanical transfer will still be created in Georgia, because the recommendations developed by these countries are general and applicable in the context of a balanced market economic system. In our country, regional policy must solve the most difficult task. This is the restoration of the economic system based on the principles of market relations. It is meant to create an appropriate supportive environment for the primary structures of the economy, including the development of micro and small businesses, to attract investments and investment activity, to increase social and industrial infrastructure. After all, it will be 
possible to create new jobs and raise the natural level of employment of the population, develop the financial market, increase the income of the population, etc. In order to accelerate the innovative development of the country and thus increase its international competitiveness, an employment strategy should be developed and implemented, which will comprehensively present measures for youth employment, their qualifications and skills tailored to the labor market, and painless involvement in labor processes [10]. When developing the labor market strategy, the system of priorities considering the vital interests of all members of the society must be accurately identified; a particular attention must be paid to the state of the more or less provided citizens, distribution of the outcomes of public industry and need for justice. Depending on the criteria selected, the social trends, principles and concrete methods of the labor market regulation may be various [11]. What is more, it should be noted the tourism sector, which had the high potentiol as one of the leading sector for economic developing of Georgia. Georgia's tourism potential is not doubtful, however, it is used only a very small part of it. In order to make real shifts to maximize the prospects of this potential, it is necessary firstly to analyze the hindering factors that are obstacle for intensive and extensive development of tourism [12]. But under covid construction this sector faced acute problems and for the future development tourism sector should overcome additional problems too which were caused by Covid- 19 .

The problem of unemployment is one of the acutest problems in Georgia and as the results of different statistical, conjunctive or social surveys evidence, often ranks first among the most important social-economic or political problems the country and Georgian people face [13].

Consequently, unemployment is one of the most important and urgent problems affecting not only the unemployed population of the country, but also general state interests. This, on its turn, puts the priority and necessity for realizing some active policy by the state on the agenda [14]. Thorough statistical analysis of unemployment is the basis for accomplishing permanent monitoring of unemployment and undertaking relevant correction measures. In addition, the study of unemployment in respect of the country in general, as well as in regional, gender, age and urban and rural respects, has a great practical importance to develop the right policy of employment, as one of the major factors to overcome poverty [15-17]. Unemployment causes not only poverty for a large part of the population in any country, but it also leads to the spiritual, mental and moral degradation of the people. It is essential to develop the appropriate educational system for that at first stage [18-19].

Given that the GEL inflation rate remains high, and the economic growth rate is a single digit, the economic crisis caused by the pandemic will significantly affect the country. In times of economic crisis, human rights such as the right to work, the right to equality, the right to security, the right to access to health care and other socio-economic rights will be particularly endangered. Probably the most acute is the problem of unemployment, because all of the above it just spreads. What is more, Underdevelopment of the labor market infrastructure leads to the situation when people do not have the opportunity and/or do not know who and where to apply for the information they need, how to look for a job and how to develop professional skills especilly taking into considaration the gender aspect. therefore, solving the problem of unemployment is one of the priority tasks of any civilized country [20-21].

At least what were the dynamics of labour market statistics? What should we expect after the pandemic is over? These are the main questions that are relevant to any country in the world today. 
According to a recent poll by the National Democratic Institute (NDI), 67\% of the population still sees unemployment as a major economic problem. The problem of unemployment is exacerbated by the coronavirus pandemic and related constraints.

According to the National Statistics Office, in the second quarter of 2020, the unemployment rate in Georgia increased by 0.9 percentage points compared to the same period last year and amounted to 12.3 percent. The employment rate fell by 0.5 percentage points to 55.9 percent. In the II quarter, compared to the corresponding quarter of the previous year, the share of employees in the total employment rate decreased by 1.6 percentage points to $48.6 \%$ (see Figure 1) [22].

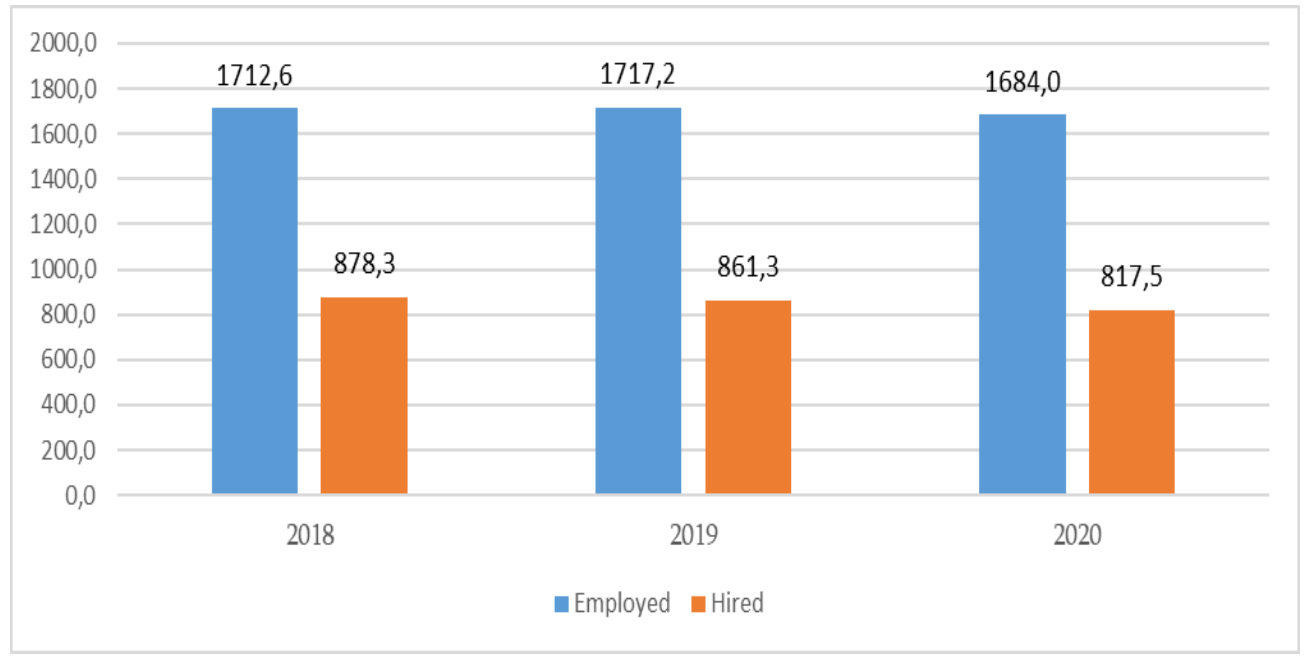

Fig. 1. Distribution of population aged 15 and older by economic status (by 2018-2020 2 quarters)

Pandemics and strict regulations (closing borders, universal quarantine, etc.) have caused significant socio-economic damage to the world, which has logically led to a reduction in jobs and incomes. However, unemployment in Georgia was one of the main challenges before the pandemic. Since 2016, the country's workforce and number of employees have been declining every year.

Statistically, the unemployment rate in the country is decreasing every year. However, in 2016-2019, the unemployment rate decreased due to the decrease in the labour force, without the increase in employment. In other words, the level of unemployment in the country is decreasing only for technical reasons, which is explained by the methodology for calculating the level of unemployment. According to the Geostat methodology, the unemployment rate is calculated as a result of the ratio of unemployed people to the labour force. Unemployment is considered only for those people who are looking for a job and can not work. Labour force (economically active population) is the total number of employed and job-seeking people. However, it should be noted that the National Statistics Office is currently working on a methodological improvement of labour market statistics, which is primarily concerned with the calculation of employment and unemployment rates. There will be particular changes in the definition of the category of employees, as under the existing project the self-employed should be excluded from the category of employees. This will radically change the employment rate and consequently adjust a number of related economic indicators. In the current situation, if a person is no longer looking for a job and the so-called "It is a hopeless workforce", it lacks both the ranks of the unemployed and the 
labour force. Such an approach explains the current statistical picture of employment and unemployment.

According to the current methodology, the economically active population in the country decreased by 106.8 thousand or 2.8 percentage points in 2012-2019 (see Figure 2) [22].

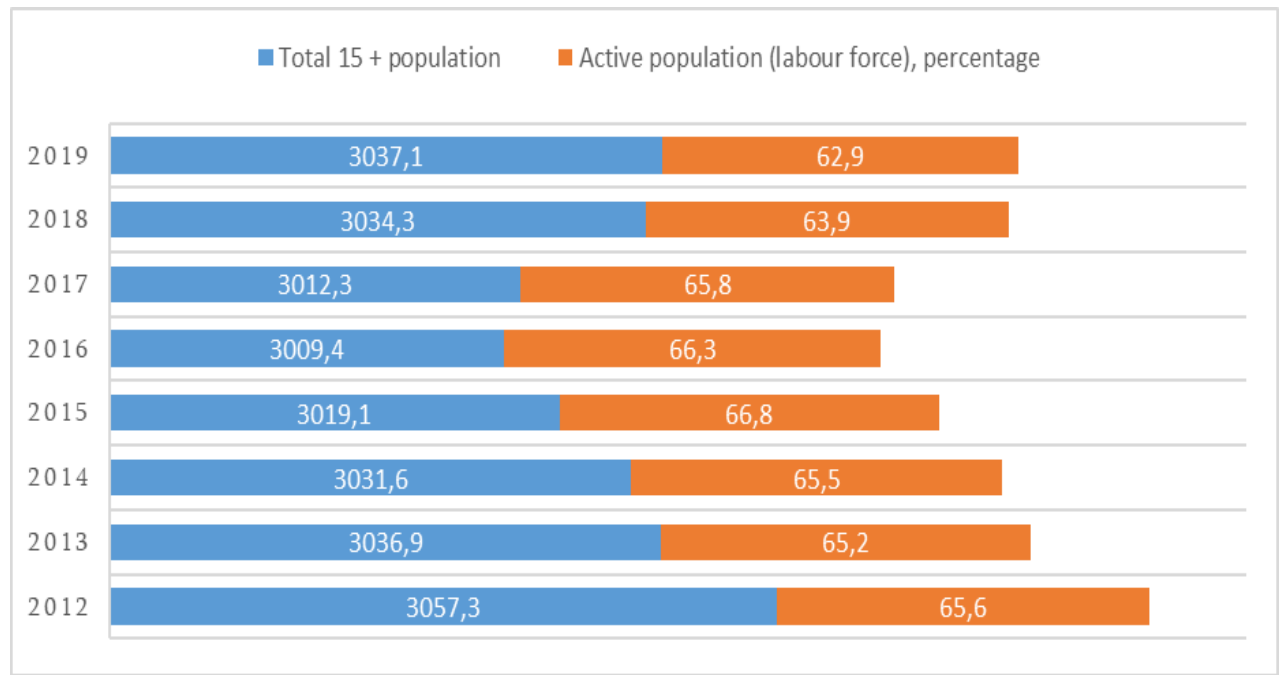

Fig. 2 . Distribution of population aged 15 and older by economic status (2012-2019)

The decline in the economically active population (labour force) in turn (as one of the factors) has led to changes in employment and unemployment rates (see Fig.3). In particular, since 2016 (when the employment rate was the highest - 57.4\%) the number of employees has been decreasing every year. In particular, in 2016-2019, the number of employees decreased by 43.6 thousand or 1.8 percentage points ) [22].
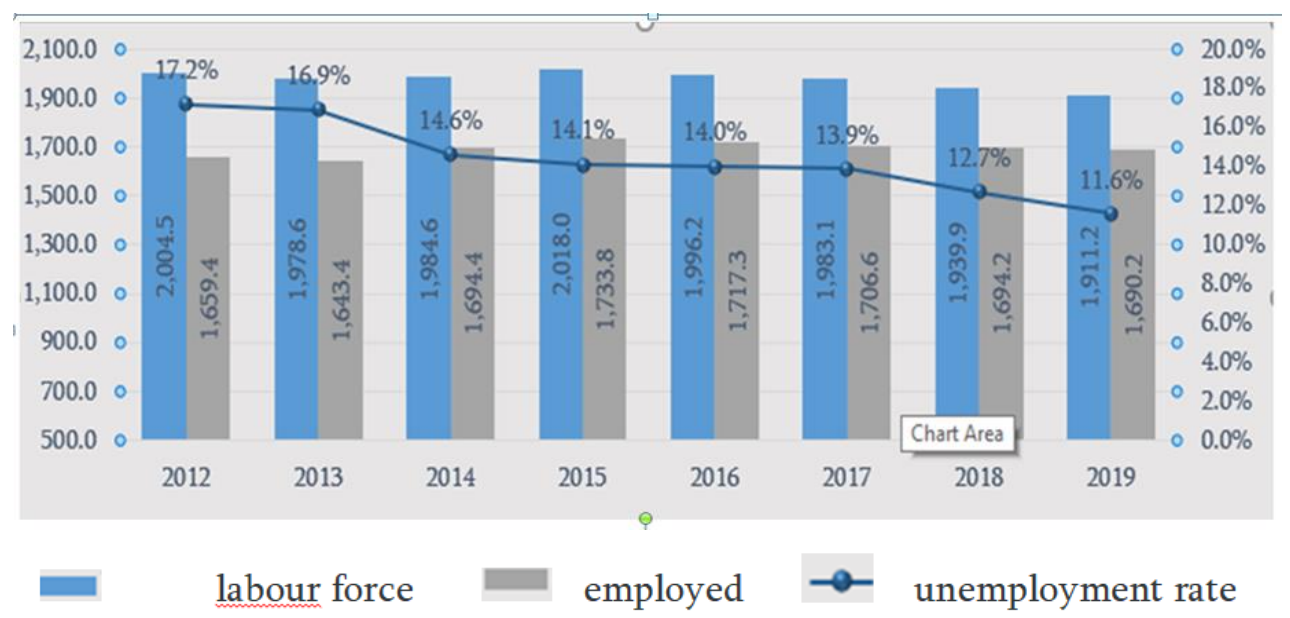

Fig. 3. Employment and Unemployment in 2012-2019 
In addition, in 2019, the employment rate was reduced at the expense of hired employees. In particular, in 2019, compared to 2018, the number of employees decreased by 4 thousand (Fig. 4) ) [22].. During this period, the number of hired employees decreased by 10.9 thousand, while the number of self-employed increased by 7 thousand. It should be noted that the share of the self-employed in the total employment rate is $49.7 \%$. The high share of the self-employed in the employment rate should be unequivocally negatively assessed. A large proportion of the self-employed are employed in agriculture / family farms, and their activities are low-productivity and low-income. However, most of them consider themselves unemployed. When a new job is created in the country, it can be filled by the self-employed, ie moved to the category of hired employees, as a result the number of unemployed will not decrease.

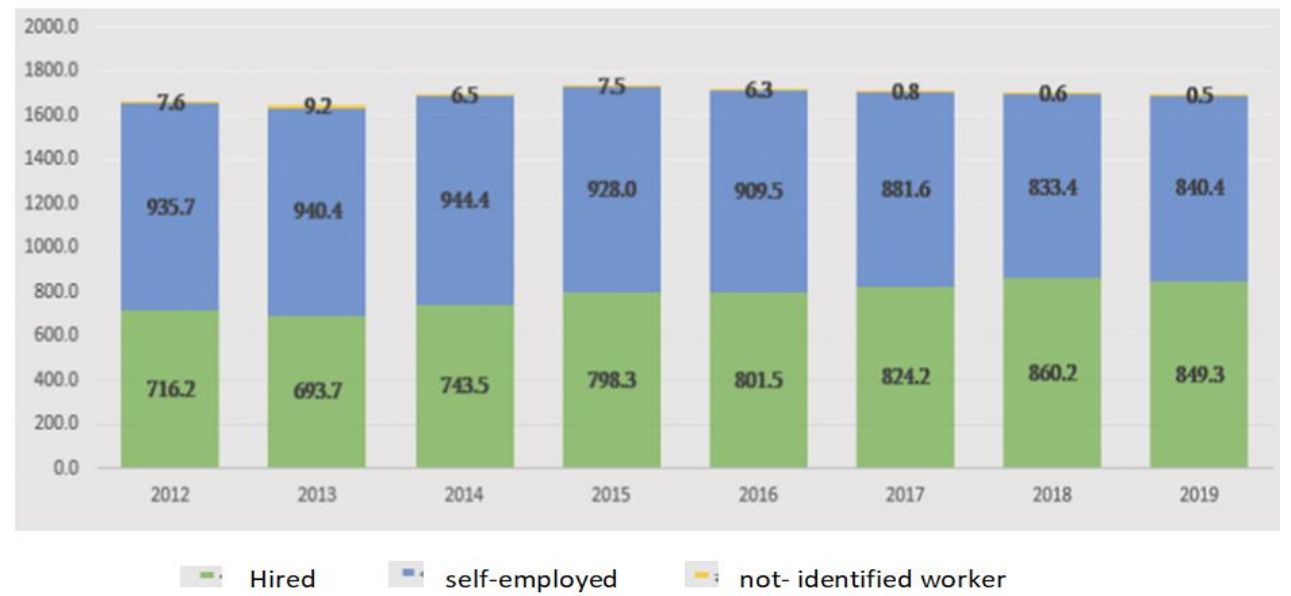

Fig. 4. Dynamics of the number of self-employed and hired employed (2012-2019)

Speaking of employment rates, it should also be noted that since 2017, the number of employees in the public sector has been growing every year, while the private sector is declining (Figure 5) [22]. In 2017-2019, 27.8 thousand people were employed in the public sector. During the same period, the number of employees in the non-governmental / private sector decreased by 54.9 thousand. The growth of employment in the public sector only increases the bureaucratic costs and burdens the state budget. The main reasons for unemployment are small economy and lack of appropriate qualifications of the labour force. Government policies should be aimed at reviving the economy, which in turn should attract large investment projects and achieve high economic growth. 


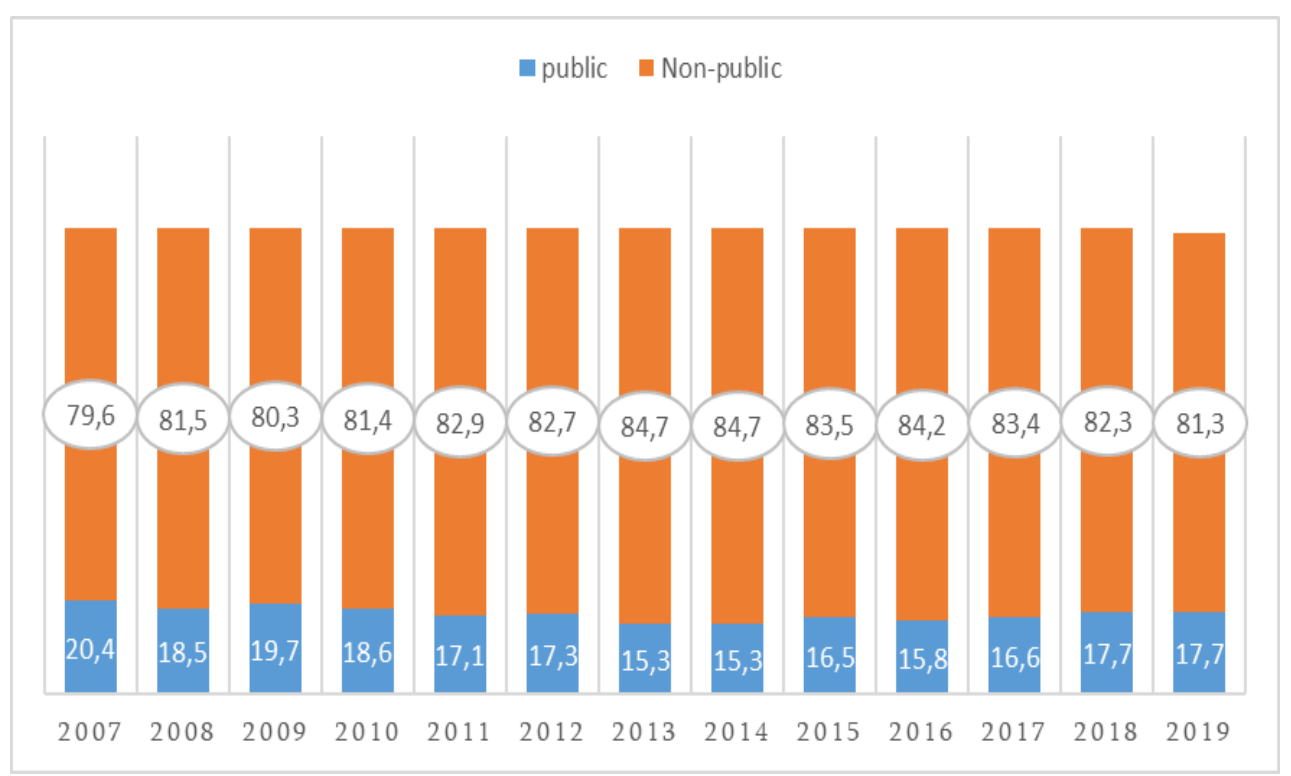

Fig. 5. Distribution of employed persons by type of ownership, 2007-2019

To sum up all the above-mentioned discussion it should be noted that in order to carry out an active labor market policy, it is necessary to implement an effective mechanism of social protection of the unemployed in parallel with the introduction of an effective monitoring system, access to health systems and at the same time to develop and implement targeted state training programs for the unemployed population of the country.

\section{References:}

1. Tsartsidze, M., Kvirkvelia, E. (2014). Poverty And Economic Development Problems In Georgia, Journal The Economics and Business, \#5, ISSN 1987-5789. 55-78.

2. Tsartsidze, M. (2013). Natural level of unemployment, factors influencing it and its assessment, Journal The Economics and Business, \#3, ISSN 1987-5789. 55-66.

3. Tugushi, M., Paresashvili, N. (2007). Unemployment and its socialeconomic outcomes in Georgia, Journal The Economics, \#3-4. 60-65.

4. Chitaladze, K. (2016). General Unemployment Data in Georgia And The Statistical Analysis. Preparation for the Future Innovative Economy, 278-283.

5. Paresashvili, N., \& Damenia, N. (2019). The Mechanisms of State Management in Agricultural Sector of Georgia. Intellectual Economics, 13(2), 105-116.

6. Gechbaia, B., Kharaishvili, E., Mamuladze, G., Goletiani, K. (2019). Current challenges of grocery market and key directions of development of agriculture in Georgia. Economic Science for Rural Development, (50), 52-60.

7. Kinkladze, R. (2015). Modern trends and prospects to develop the agrarian sector of Georgia. Procedia-Social and Behavioral Sciences, 213(1), 562-568. 
8. Abesadze, N., \& Javakhishvili, I. (2017). Indicators of the growing competitiveness of the Georgian production on the European market and anticipated trends. Financial and credit activity: problems of theory and practice, 1(22), 40-45.

9. Paresashvili, N., Kinkladze, R., Chitaladze, K., Nadjafova, Z., \& Edzgveradze, T. (2020). Labor market management mechanisms in Georgia according to current trends. Economic and Social Development: Book of Proceedings, 361-370.

10. Okruashvili, N., \& Paresashvili, N. (2019). Youth unemployment in Georgia and the ways for its reduction. Challenges of Globalization in Economics and Business, .318325.

11. Paresashvili, N. (2015). Major mechanisms to develop the strategies of the labor market in Georgia. Procedia-Social and Behavioral Sciences, 213, 574-579.

12. Paresashvili, N., Chitaladze, K. (2019). Main Challenges of Tourism Development Management in Georgia. Economic and Social Development: Book of Proceedings, 1426-1432.

13. Abesadze, N. (2014). Statistics of unemployment in Georgia. Wirtschaft und Management: Theorie und Praxis, 15-16.

14. Kinkladze, R. (2011). Unemployment Trends in Georgia. Journal Of The Social Economics, (12), 54-70.

15. Abesadze, N., Paresashvili, N. (2018). Gender Aspects Of Youth Employment In Georgia. Ecoforum Journal, 7(1).

16. Paresashvili, N., Abesadze , N. (2018). Main Tendencies of Youth Unemployment and the Regulation Mechanisms for Decreasing Its Rate in Georgia. International Journal of Economics and Management, 12(5), 634-638.

17. Paresashvili, N., Abesadze, N. (2014). Statistics of unemployment in Georgia, Economy and Management: Theory and Practice, 2, 15-20.

18. Kharaishvili, E., \& Natsvlishvili, I. (2019). Challenges of re-connecting entrepreneurship and business education at universities (evidence from Georgia).

19. Kharaishvili, E., \& Natsvlishvili, I. (2019). Impact of international educational migration in the context of globalization og higher education (case of Georgia).

20. Paresashvili, N., Okruashvili, N., Edzgveradze, T. (2020). Global Challenges in the of Human Capital Formation Process (The Case of Gergia); Management: Strategic Imperatives And Trends Of Transformations, ISBN 978-966-926-342-1, 128-139.

21. Kurashvili, G., \& Kinkladze, R. (2016). Women's Migration Processes from Georgia. Preparation for the Future Innovative Economy, 308-313.

22. www. geostat.ge Official web page of National Statistics Office of Georgia, last access $15 / 09 / 2020$. 